\title{
Tularemia pulmonar: la gran simuladora
}

\section{Patricia Mimoso-Bartolomé1, Luis Antonio Marcos-Martínez' , Elena Brage-Allegue', Ester Hernández-Martín', Emilio Juárez-Moreno²}

'Servicio de Medicina Interna, Hospital El Bierzo, Ponferrada, España

${ }^{2}$ Servicio de Neumología, Hospital El Bierzo, Ponferrada, España

Recibido: 08/10/2021

Aceptado:03/12/2021

En línea: 31/12/2021

Citar como: Mimoso-Bartolomé P, Marcos-Martínez LA, Brage-Allegue E, Hernández-Martín E, Juárez-Moreno E. Tularemia pulmonar: la gran simuladora. Rev Esp Casos Clin Med Intern (RECCMI). 2021 (dic); 6(3): 22-25. doi: 10.32818/reccmi.a6n3a8.

Cite this as: Mimoso-Bartolomé P, Marcos-Martínez LA, Brage-Allegue E, Hernández-Martín E, Juárez-Moreno E. Pulmonary tularemia: the great pretender. Rev Esp Casos Clin Med Intern (RECCMI). 2021 (Dec); 6(3): 22-25. doi: 10.32818/reccmi.a6n3a8.

Autor para correspondencia: Patricia Mimoso-Bartolomé. patriciamimosob@saludcastillayleon.es

\section{Palabras clave}

$\checkmark$ Tularemia

$\checkmark$ Nódulo pulmonar

\section{Resumen}

La tularemia es una zoonosis causada por la bacteria Francisella tularensis que puede provocar diferentes cuadros clínicos pudiendo simular otras enfermedades. Un varón de 54 años consultó por cuadro febril sin claro foco de origen en el que se halló una imagen compatible con masa pulmonar. En el estudio se obtiene una serología positiva para tularemia por lo que se inicia terapia antibiótica, pero se prosiguió estudio de la masa pulmonar. Tras tratamiento antibiótico se evidenció resolución de la imagen radiológica. La tularemia pulmonar es una enfermedad capaz de simular otras entidades respiratorias, incluso procesos malignos.

Abstract
Tularemia is a zoonosis caused by the bacterium Francisella tularensis that can cause different clinical pictures
and could simulate other diseases. A 54-year-old man consulted for febrile symptoms without a clear source of
origin in which an image compatible with a pulmonary mass was found. The serology was positive for tularemia,
so antibiotic therapy was started, but the pulmonary mass was further studied. After antibiotic treatment, the
radiological image resolved. Pulmonary tularemia is a disease capable of simulating other respiratory entities, in-
cluding malignant processes.

\section{Puntos destacados}

$\triangle$ La tularemia pulmonar es una enfermedad que puede simular otras entidades, tanto infecciosas como neoplásicas.

$\checkmark$ El antecedente epidemiológico es clave para despertar la sospecha diagnóstica.

- El estudio serológico puede ayudar a un diagnóstico precoz y evitar complicaciones y exploraciones invasivas.

\section{Introducción}

La tularemia es una zoonosis causada por la bacteria Francisella tularensis, cocobacilo gram negativo, ampliamente distribuida en el hemisferio norte. El ser humano adquiere la infección por diferentes mecanismos: contacto directo con animales enfermos (conejos, liebres, roedores y otros mamíferos), a través de vectores (insectos como moscas, mosquitos y garrapatas), ingesta de alimentos (carne o agua contaminadas) o por inhalación.

La presentación clínica y la gravedad dependen de la subespecie responsable, del mecanismo de infección y del estado inmunológico del huésped.
Tras un período de incubación, que oscila entre 3-6 días (puede alcanzar las 3 semanas), el paciente comienza con malestar general, dolores generalizados, cefalea, astenia, anorexia y fiebre elevada. Se diferencian seis formas clínicas, que dependen fundamentalmente del modo de adquisición: ulceroglandular, glandular, oculoglandular, faríngea, tifoidea y neumónica; pudiendo variar desde una enfermedad asintomática o leve hasta una sepsis aguda rápidamente fatal. Además, pueden coexistir en un mismo paciente distintas modalidades clínicas ${ }^{1}$

A continuación, presentamos un caso de tularemia pulmonar que se presentó de una forma excepcional ya que radiológicamente simulaba una neoplasia pulmonar.

\section{Caso clínico}

Antecedentes, enfermedad y exploración física

Varón de 54 años, exminero de interior y exfumador de 30 paquetes/año hasta los 46 años. Reside en medio rural de la comarca de El Bierzo, aunque sin contacto directo con animales ni ganado. Entre sus antecedentes personales 
destaca haber padecido 8 años antes un linfoma de Hodgkin clásico tipo celularidad mixta estadio IA, tratado mediante quimioterapia y radioterapia; en remisión completa desde entonces.

Unos 14 días antes de la consulta el paciente había pasado un fin de semana en un pueblo de Tierra de Campos, realizando labores en una huerta.

Consulta por cuadro de 12 días de evolución consistente en fiebre, inicialmente elevada de hasta $39^{\circ} \mathrm{C}$ con afectación del estado general y astenia intensa. Los días siguientes la fiebre era de menor grado, predominio nocturno, mejor tolerada y acompañada de sudoración profusa. Hubo discreta pérdida de peso no cuantificada. La exploración física fue estrictamente normal.

\section{Pruebas complementarias}

Cuando le vemos en consulta el paciente se acababa de realizar una tomografía axial computerizada (TAC) corporal solicitada por Hematología que mostraba una masa de $3 \mathrm{~cm}$ de diámetro en el segmento ápico-posterior del lóbulo pulmonar superior izquierdo (figura 1).

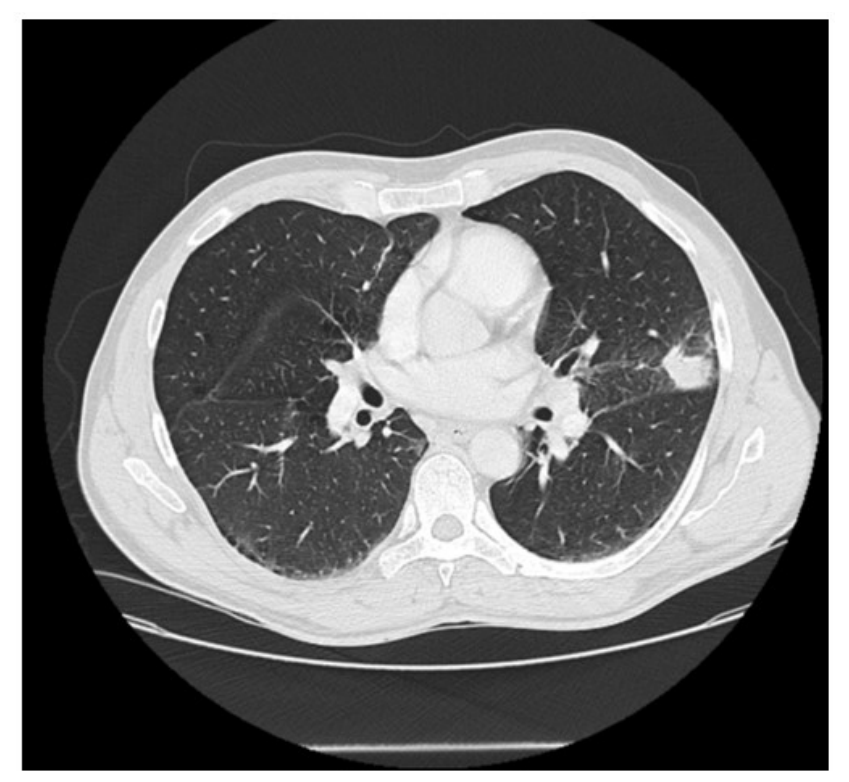

Figura 1. TAC al diagnóstico: Masa de $3 \mathrm{~cm}$ de diámetro en el segmento ápico-posterior del lóbulo pulmonar superior izquierdo.

Se le solicitó estudio analítico en el que destacaba leucocitosis neutrofílica y elevación de reactantes de fase aguda (PCR 9 mg/dL [ $<1 \mathrm{mg} / \mathrm{dL}]$ y VSG 61 $\mathrm{mm} / \mathrm{h}[0-15 \mathrm{~mm} / \mathrm{h}])$, con el resto de los parámetros de hematimetría, bioquímica hemática y sistemático de orina sin alteraciones.

El factor reumatoide, los anticuerpos antinucleares y anticitoplasma de neutrófilo resultaron negativos. Los marcadores tumorales CEA, CA19.9, PSA, SCC, Cyfra 21.1, NSE, alfafetoproteína y B2-microglobulina eran normales. La prueba de detección de infección tuberculosa mediante método de liberación de interferón gamma (QuantiFERON-TB ${ }^{\circledR}$ ) fue negativa. Los hemocultivos y urocultivo también resultaron negativos. Las serologías frente a VHB, VHC, VIH, lúes, toxoplasma, Brucella, VEB, Leishmania, Ricketssia conorii, Bartonella, Borrelia fueron negativas.

La determinación serológica frente a Coxiella burnetii lgG fase II era positiva a título 1/128, sin modificarse en fase de convalecencia. Por último, la serología para Francisella tularensis mediante ELISA resultó positiva enviándose muestra para confirmación mediante microaglutinación que resultó también positiva a título 1/128.

\section{Evolución}

Estamos ante un paciente exfumador con un síndrome febril de origen no aclarado y una masa pulmonar. Tras una primera serología positiva para tularemia y aún pendiente del test de confirmación, se decide tratamiento con ciprofloxacino 500 mg cada 12 horas durante 14 días vía oral, presentando una evolución favorable con desaparición de la fiebre, mejoría de la sintomatología general y descenso de los reactantes de fase aguda.

Se decide continuar estudio de la masa pulmonar mediante realización de una biopsia transtorácica y tomografía de emisión de positrones (PET-TAC). La histología resultó compatible con proceso inflamatorio crónico sin signos de malignidad y la PET-TAC evidenciaba la existencia de un nódulo pulmonar izquierdo de 1,1 x 1,3 cm y adenopatías hiliomediastínicas y supracalviculares derechas con captación de 18F-FDG (figuras 2 y 3 ).

En el control radiológico con nueva TAC pasado un mes se comprueba la completa desaparición de la masa pulmonar (figura 4). Finalmente, la microaglutinación para tularemia a las 2 semanas de la primera determinación dio un título de 1/8192.

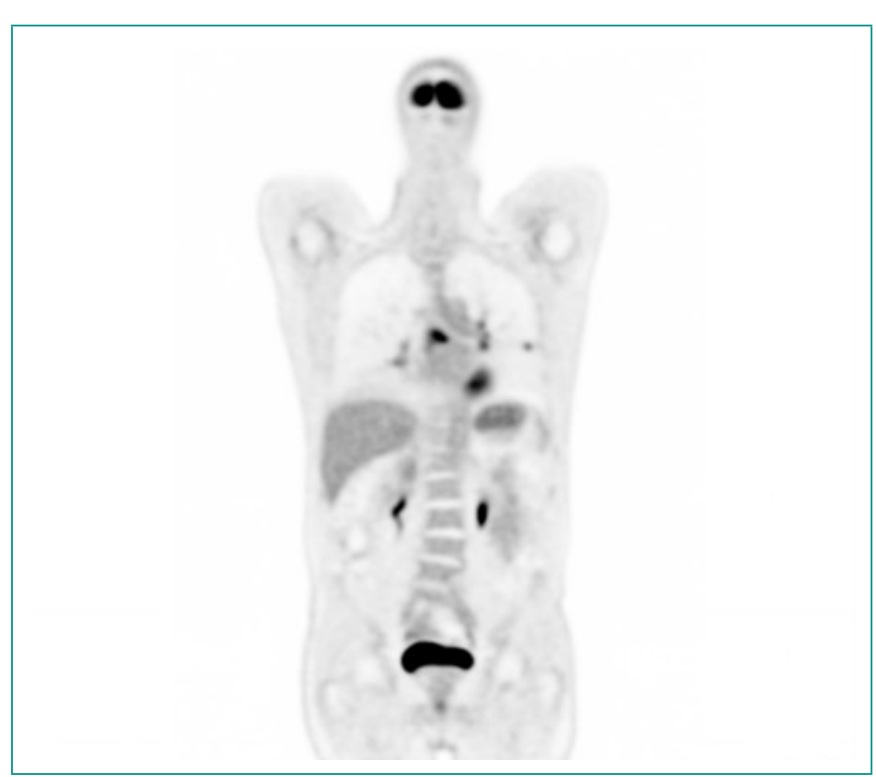

Figura 2. Imagen PET: Nódulo pulmonar izquierdo y adenopatías hiliomediastínicas con captación de 18F-FDG.

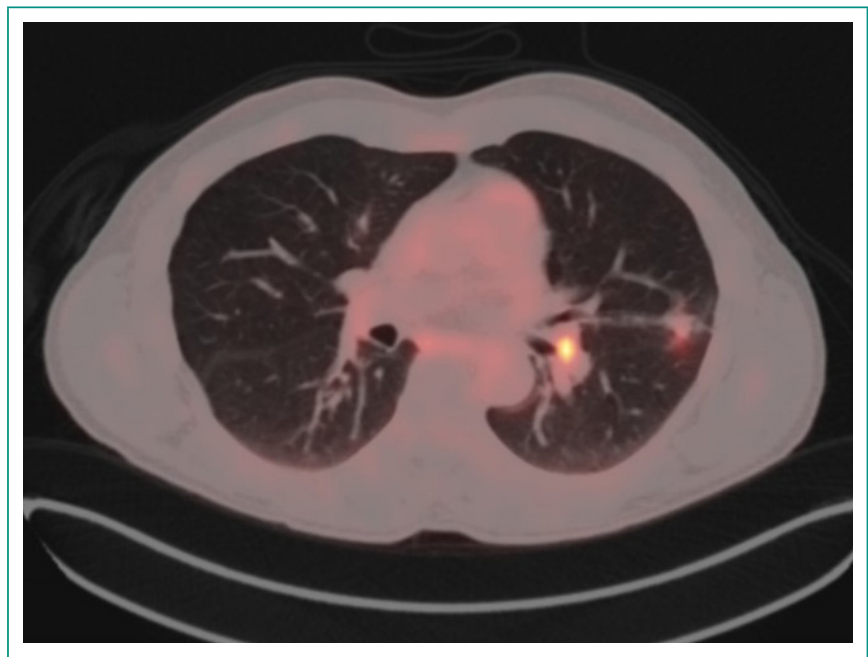

Figura 3. Imagen PET-TAC: Nódulo pulmonar izquierdo y adenopatías hiliomediastínicas con captación de 18F-FDG. 




Figura 4. TAC de control tras finalización del tratamiento: desaparición de la masa pulmonar.

\section{Diagnóstico}

Tularemia pulmonar.

\section{Discusión y conclusiones}

La tularemia pulmonar puede aparecer hasta en un 30\% de los casos de dicha enfermedad, aunque en las series descritas en nuestro medio más cercano la neumonía aparece solo entre el 1,5 y 6\% de las ocasiones². La adquisición puede ocurrir tanto por diseminación hematógena, en el contexto de cualquier otra forma de la enfermedad, como por inhalación directa, siendo esta forma primaria un riesgo para determinadas profesiones como esquiladores de ovejas, granjeros y personal de laboratorio ${ }^{3}$.

Las manifestaciones radiológicas características más comunes incluyen consolidaciones uni o bilaterales, opacidades en «árbol en brote», adenopatías hiliares, derrame pleural y pericarditis, pudiendo simular otras entidades como neumonía de otra naturaleza, tuberculosis o linfoma ${ }^{3}$.

La presentación radiológica en forma de nódulo o masa pulmonar que puede llevar a la confusión con una neoplasia pulmonar resulta más excepcional, existiendo pocos casos documentados en la literatura (tabla 1).

Naughton et al. ${ }^{4}$ describen el caso de una masa pulmonar de 3,3 $\times 3 \mathrm{~cm}$ en un paciente que había sido tratado unos meses antes de una leucemia mieloblástica aguda mediante quimioterapia y trasplante de células madre periféricas. El diagnóstico se realizó mediante cultivo del material obtenido en una punción transtorácica.

El caso de otro paciente con nódulos pulmonares múltiples que seguía terapia inmunosupresora debido a una artritis reumatoide podría sugerirnos que la depresión del sistema inmune pudiera favorecer este tipo de presentación radiológica ${ }^{5}$. Para el diagnóstico también precisó cultivo de la muestra de una biopsia pulmonar.
Ya en nuestro medio Reguero et al. ${ }^{3}$ describen un paciente con cuadro febril y una masa pulmonar de $4 \mathrm{~cm}$ aparentemente sólida que sugería la existencia de una neoplasia; posteriormente evolucionó hacia nódulos múltiples y lesiones en «árbol en brote», simulando una tuberculosis. El diagnóstico se realizó mediante serología.

Por último, Rubio et al. ${ }^{6}$ describen el caso de una masa pulmonar coexistente con una tularemia ulceroglandular en una mujer durante el brote epidémico acaecido en Castilla y León en 1998. La imagen se resolvió tras tratamiento antibiótico.

La serie más amplia descrita de tularemia simulando un cáncer de pulmón corresponde a cuatro casos consecutivos, muy similares al nuestro, atendidos en un hospital suizo ${ }^{7}$. Todos cursaban con adenopatías mediastínicas satélites y en uno los nódulos eran múltiples. Para su evaluación se realizó PET-TAC que mostraba, al igual que ocurría en nuestro paciente, captación patológica sugestiva de malignidad. Para el diagnóstico se emplearon exploraciones invasivas.

Más recientemente, Mambie et al..$^{8}$ describen un caso de masa pulmonar con adenopatía satélite y captación patológica en PET-TAC. Se llegó al diagnóstico tras exéresis quirúrgica.

La tularemia pulmonar es una entidad que puede simular otras enfermedades respiratorias, tanto infecciosas como neoplásicas, siendo difícil su diagnóstico cuando no se acompaña de otras manifestaciones características de la enfermedad.

Se debe sospechar en pacientes con clínica compatible y antecedente epidemiológico, ya que puede ser una enfermedad grave e incluso mortal si no se trata precozmente. La solicitud de determinaciones serológicas puede ayudar a un diagnóstico precoz y evitar la realización de exploraciones invasivas con su consiguiente iatrogenia.

\section{Bibliografía}

1. Geijo Martínez MP, Rosa Herranz C, Meiling Díaz de Tuesta Chow-Quan A. Tularemia. Medicine. 2002; 8(65): 3449-3454. doi: 10.1016/503045412(02)70643-4

2. Bachiller Luque P, Pérez Castrillon JL, Martín Luquero M, Mena FJ, De La Lama J, Pérez Pascual P, et al. Descripción preliminar de un brote epidémico de tularemia en Valladolid. Rev Clin Esp. 1998; 198(12): 789-93.

3. Reguero Llorente E, Arauzo Álvarez E. Pulmonary tularemia. Radiología. 2015; 57(6): 529-30. doi: 10.1016/j.rx.2015.06.001.

4. Naughton M, Brown R, Adkins D, DiPersio J. Tularemia - an unusual cause of a solitary pulmonary nodule in the post-transplant setting. Bone Marrow Transplantation, 1999; 24(2): 197-9. doi: 10.1038/sj.bmt.1701863.

5. Alias T, Kazem Fallahzadeh M, Berhe M, MD. Tularemia presenting as pulmonary nodules in an immunocompromised patient. Proc (Bayl Univ Med Cent). 2017; 30(2): 175-176. doi: 10.1080/08998280.2017.11929573.

6. Rubio T, Gaztelu MT, García C, Urbieta M, Alonso JL. Mujer de 49 años con lesión cutánea, hipoxemia y masa pulmonar. Enferm Infecc Microbiol Clin. 1999; 17: 247-248.

7. Fachinger P, Mauro Tini G, Grobholz R, Gambazzi F, Fankhauser H, Irani S. Pulmonary tularaemia: all that looks like cancer is not necessarily cancerCase reports of four consecutive cases. BMC Pulm Med. 2015; 15: 27. doi: 10.1186/s12890-015-0026-y.

8. Mambie A, Wallet F, Scherman L, Armand S, Vervelle C, Faure Ket al. Neither Neoplasia nor Tuberculosis, but Francisella. Open Forum Infect Dis. 2016; 3(2): ofw080. doi: 10.1093/ofid/ofw080. 
Patricia Mimoso-Bartolomé, Luis Antonio Marcos-Martínez, Elena Brage-Allegue, Ester Hernández-Martín, Emilio Juárez-Moreno Tularemia pulmonar: la gran simuladora

\begin{tabular}{|c|c|c|c|c|c|c|c|c|c|c|c|}
\hline & $\begin{array}{l}\text { Edad } \\
\text { (años) }\end{array}$ & Sexo & $\begin{array}{l}\text { Vector } \\
\text { (sospecha) }\end{array}$ & $\begin{array}{c}\text { Tiempo } \\
\text { hasta el } \\
\text { diagnóstico }\end{array}$ & $\begin{array}{l}\text { Hallazgos } \\
\text { TC al } \\
\text { diagnóstico }\end{array}$ & $\begin{array}{l}\text { Uso de técnicas } \\
\text { invasivas para el } \\
\text { diagnóstico }\end{array}$ & $\begin{array}{c}\text { Serología } \\
\text { F. tularensis }\end{array}$ & $\begin{array}{c}\text { PCR } \\
\text { muestra } \\
\text { biológica }\end{array}$ & $\begin{array}{l}\text { Tratamiento } \\
\text { empleado }\end{array}$ & Evolución & $\begin{array}{l}\text { Hallazgos } \\
\text { TC tras el } \\
\text { tratamiento }\end{array}$ \\
\hline $\begin{array}{l}\text { Fachinger } \\
\text { et al. }{ }^{9}\end{array}$ & 62 & Varón & $\begin{array}{l}\text { Heces de } \\
\text { conejo }\end{array}$ & 14 semanas & $\begin{array}{l}\text { Masa hilar, } \\
\text { nódulo } \\
\text { pulmonar, } \\
\text { adenopatías } \\
\text { mediastínicas }\end{array}$ & $\begin{array}{c}\text { EBUS-PAFF } \\
\text { (linfocitos, necrosis, } \\
\text { agregados de células } \\
\text { epiteloides) } \\
\text { Biopsia quirúrgica } \\
\text { masa hiliar } \\
\text { (granuloma } \\
\text { necrotizante) }\end{array}$ & Positiva & Positiva & $\begin{array}{l}\text { 10) Doxiciclina } \\
\text { 20) Ciprofloxacino } \\
+ \text { gentamicina }\end{array}$ & $\begin{array}{c}\text { Recurrencia } \\
\text { tras } \\
\text { doxiciclina }\end{array}$ & $\begin{array}{l}\text { Lesión } \\
\text { residual }\end{array}$ \\
\hline $\begin{array}{l}\text { Fachinger } \\
\text { et al. }{ }^{9}\end{array}$ & 49 & Varón & Garrapata & 12 semanas & $\begin{array}{l}\text { Nódulos } \\
\text { pulmonares } \\
\text { múltiples, } \\
\text { adenopatías } \\
\text { hiliares y } \\
\text { mediastínicas }\end{array}$ & $\begin{array}{c}\text { EBUS-PAFF } \\
\text { (linfocitos, necrosis, } \\
\text { agregados de células } \\
\text { epiteloides) }\end{array}$ & Positiva & Positiva & Ciprofloxacino & Remisión & $\begin{array}{c}\text { Pequeña } \\
\text { lesión residual }\end{array}$ \\
\hline $\begin{array}{l}\text { Fachinger } \\
\text { et al. }{ }^{9}\end{array}$ & 52 & Varón & Desconocido & 9 semanas & $\begin{array}{l}\text { Masa hiliar, } \\
\text { adenopatías } \\
\text { hiliares y } \\
\text { mediastínicas }\end{array}$ & $\begin{array}{c}\text { EBUS-PAFF } \\
\text { (linfocitos, necrosis, } \\
\text { agregados de células } \\
\text { epiteloides) }\end{array}$ & Positiva & $\begin{array}{c}\text { No } \\
\text { realizada }\end{array}$ & Ciprofloxacino & Remisión & $\begin{array}{l}\operatorname{Sin} \\
\text { alteraciones }\end{array}$ \\
\hline $\begin{array}{l}\text { Fachinger } \\
\text { et al. }{ }^{9}\end{array}$ & 40 & Varón & Desconocido & 2 semanas & $\begin{array}{l}\text { Masa en } \\
\text { lóbulo medio } \\
\text { y adenopatías } \\
\text { subcarinales }\end{array}$ & $\begin{array}{c}\text { EBUS-PAFF } \\
\text { (linfocitos normales) }\end{array}$ & Positiva & Positiva & Ciprofloxacino & Remisión & Cicatriz hiliar \\
\hline $\begin{array}{l}\text { Rubio } \\
\text { et al. }{ }^{8}\end{array}$ & 49 & Mujer & $\begin{array}{c}\text { Ganado } \\
\text { ovino/liebres }\end{array}$ & 9 días & $\begin{array}{c}\text { Masa hiliar } \\
\text { derecha, } \\
\text { adenopatía } \\
\text { ventana } \\
\text { aortopulmonar }\end{array}$ & $\begin{array}{l}\text { Broncoscopia- } \\
\text { biopsia } \\
\text { trasbronquial } \\
\text { (sin datos de } \\
\text { malignidad) }\end{array}$ & Positiva & $\begin{array}{l}\text { No } \\
\text { realizada }\end{array}$ & $\begin{array}{l}\text { Gentamicina y } \\
\text { doxiciclina }\end{array}$ & Remisión & $\begin{array}{l}\sin \\
\text { alteraciones }\end{array}$ \\
\hline $\begin{array}{l}\text { Alias et } \\
\text { al. }^{7}\end{array}$ & 51 & Varón & Conejos & 2 semanas & $\begin{array}{l}\text { Nódulos } \\
\text { pulmonares } \\
\text { bilaterales, } \\
\text { adenopatías } \\
\text { mediastínicas } \\
\text { y derrame } \\
\text { pleural } \\
\text { derecho }\end{array}$ & $\begin{array}{l}\text { Biopsia de nódulo } \\
\text { pulmonar (cultivo } \\
\text { positivo para F. } \\
\text { tularensis) }\end{array}$ & No realizada & $\begin{array}{l}\text { No } \\
\text { realizada }\end{array}$ & $\begin{array}{l}\text { Gentamicina y } \\
\text { ciprofloxacino }\end{array}$ & Remisión & Mejoría \\
\hline $\begin{array}{l}\text { Naughton } \\
\text { et al. }{ }^{6}\end{array}$ & 61 & Varón & $\begin{array}{l}\text { Desconocido } \\
\text { (reside en } \\
\text { medio rural) }\end{array}$ & 2 semanas & $\begin{array}{l}\text { Nódulo } \\
\text { pulmonar } \\
\text { lóbulo inferior } \\
\text { derecho }\end{array}$ & $\begin{array}{l}\text { PAAF nódulo } \\
\text { pulmonar } \\
\text { y biopsias } \\
\text { trasbronquiales } \\
\text { (cultivo positivo para } \\
\text { F. tularensis) }\end{array}$ & No realizada & $\begin{array}{l}\text { No } \\
\text { realizada }\end{array}$ & Ciprofloxacino & Remisión & $\begin{array}{l}\operatorname{Sin} \\
\text { alteraciones }\end{array}$ \\
\hline $\begin{array}{l}\text { Mambie } \\
\text { et al. }{ }^{10}\end{array}$ & 70 & Varón & $\begin{array}{c}\text { Desconocido } \\
\text { (paciente } \\
\text { cazador) }\end{array}$ & -- & $\begin{array}{c}\text { Masa lóbulo } \\
\text { superior } \\
\text { derecho y } \\
\text { linfadenopatías }\end{array}$ & $\begin{array}{l}\text { Broncoscopia (sin } \\
\text { lesiones) } \\
\text { Mediastinoscopia } \\
\text { y biosia (Necrosis y } \\
\text { células gigantes) } \\
\text { Segmentectomía } \\
\text { y linfadenectomía } \\
\text { (granuloma } \\
\text { necrótico sin células } \\
\text { sugestivas de } \\
\text { malignidad) }\end{array}$ & Positiva & Positiva & Ciprofloxacino & Remisión & -- \\
\hline $\begin{array}{l}\text { Mimoso- } \\
\text { Bartolomé } \\
\text { et al. }\end{array}$ & 54 & Varón & $\begin{array}{c}\text { Desconocido } \\
\text { (¿topillos?) }\end{array}$ & 2 semanas & $\begin{array}{c}\text { Masa en } \\
\text { lóbulo superior } \\
\text { izquierdo }\end{array}$ & $\begin{array}{c}\text { Biopsia trastorácica } \\
\text { (proceso inflamatorio } \\
\text { crónico) }\end{array}$ & Positiva & $\begin{array}{l}\text { No } \\
\text { realizada }\end{array}$ & Ciprofloxacino & Remisión & $\begin{array}{l}\sin \\
\text { alteraciones }\end{array}$ \\
\hline
\end{tabular}

Tabla 1. Resumen de los casos de tularemia pulmonar descritos en la literatura. 